\title{
Long-Term Variability of Thermohaline Characteristics of the Azov Sea Based on the Numerical Eddy-Resolving Model
}

\author{
A. I. Mizyuk ${ }^{1, *}$, G. K. Korotaev ${ }^{1}$, A. V. Grigoriev ${ }^{2}$, O. S. Puzina ${ }^{1}$, \\ P. N. Lishaev \\ ${ }^{1}$ Marine Hydrophysical Institute of RAS, Sevastopol, Russian Federation \\ ${ }^{2}$ N. N. Zubov State Oceanographic Institute, Moscow, Russian Federation \\ * artem.mizyuk@mhi-ras.ru
}

Purpose. Decline of the river Don runoff to its historic minima, as well as intensive cyclonic activity and abnormal advection of the Black Sea waters led to the fact that in 2014-2016, very high salinity values (up to $12 \mathrm{psu}$ ) were observed in the Taganrog Bay. Under certain hydrometeorological conditions, salt water can penetrate deep into the river Don mouth. Therefore, study of changes in the Azov Sea hydrothermodynamics is rather an actual problem, which is proposed to be solved by numerical modeling.

Methods and Results. The paper represents the methodology for carrying out long-term model runs for joint dynamics of the Black, Azov and Marmara seas based on the eddy-resolving configuration of the NEMO modeling framework. A new-generation ERA5 reanalysis with a sufficiently high spatial resolution was used for the first time as a atmospheric forcing for the region. New information on the rivers Don and Kuban' runoffs were used and adjustment simulations were done to obtain the initial conditions. The results were verified based on the data from coastal hydrometeorological stations in the Sea of Azov. Some results of model simulations for the period from mid-2007 to 2016 are represented. A positive salinity trend in the basin of the Azov Sea is well pronounced. Surface boundary conditions for the heat flux were corrected for the purpose of carrying out simulations without ice modeling and reproducing adequate temperature values of the Azov Sea waters. Conclusions. The performed numerical experiments showed applicability for the developed model regional configuration to further investigations. However, more detailed analysis of the results obtained for the Black Sea basin is required. Consideration of the basic external conditions in modeling made it possible to reproduce positive tendency of salinity in the Sea of Azov. The temperature simulation results indirectly agree with the sea ice data.

Keywords: numerical ocean modeling, Sea of Azov, ERA5, free-run simulations, verification, Black Sea, Euxinus cascade.

Acknowledgments: the investigation is carried out at the RFBR financial support (grant No. 18-0580025\18 "Dangerous phenomena").

For citation: Mizyuk, A.I., Korotaev, G.K., Grigoriev, A.V., Puzina, O.S. and Lishaev, P.N., 2019. Long-Term Variability of Thermohaline Characteristics of the Azov Sea Based on the Numerical Eddy-Resolving Model. Physical Oceanography, [e-journal] 26(5), pp. 438-450. doi:10.22449/1573160X-2019-5-438-450

DOI: $10.22449 / 1573-160 X-2019-5-438-450$

(C) 2019, A. I. Mizyuk, G. K. Korotaev, A. V. Grigoriev, O. S. Puzina, P. N. Lishaev

(C) 2019, Physical Oceanography

\section{Introduction}

The Sea of Azov is known for its uniquely high fish productivity which is ensured by a large ratio of river runoff to the sea volume. This determines the low salinity of its waters and a high concentration of nutrients ${ }^{1}$. However,

${ }^{1}$ Simonov, A.I. and Altman, E.N., ed., 1991. Hydrometeorology and Hydrochemistry of the USSR Seas, Vol. IV: Black Sea, Iss. 1: Hydrometeorological Conditions. Saint Petersburg: Gidrometeoizdat, 442 p. (in Russian). 
notable changes in the Sea of Azov hydrological regime have recently been observed due to a significant reduction in river runoff (the Don, the Kuban, the Mius, etc.). As a result of reduced runoff, the level difference of the Azov and Black Seas decreases. This leads to the increase of the salt input from the Black Sea through the Kerch Strait and the change of total balance of salt and fresh waters in the basin. These changes are especially noticeable in the Taganrog Bay, where significant salinization of the waters is observed at separate intervals. Under certain hydrometeorological conditions salt water penetrates even into the Don River estuary, where freshwater intake is located. In addition to the water salinization, the influx of waste products of some marine organisms developing under new hydrological conditions is also observed at the estuary. The quality of the water used to provide the habitancy can be significantly reduced.

The Sea of Azov is characterized by significant spatial heterogeneity of salinity. In the area from the Don River delta to the Kerch Strait, salinity increases from $0.5-0.7$ to $13-14 \%$. The sharpest salinity gradient is naturally formed in the estuarine-type Taganrog Bay. Here the centuries-old, seasonal and surge variations of the thermohaline regime are clearly manifested. Reduction of the Don River runoff to a historic minimum, along with intensive cyclonic activity and anomalous advection of the Black Sea waters, led to the fact that in 2014-2016 an abnormally high salinity (up to $12 \%$ ) was observed in the Taganrog Bay [1]. Therefore, one of the most important applied problems is the assessment of such a dangerous phenomenon as an abnormal change in hydrothermodynamics and the ecosystem of the basin under effect of changes in river runoff and economic activity.

This problem can be solved in the system of forecasting the hydrophysical parameters, which would also allow us to evaluate the characteristics of water quality. Currently, there are no systems providing information aboutthe Sea of Azov or their results are not publicly available. In systems for predicting the state of the oceans, for example, Copernicušs Marine Environment Monitoring Service $(C M E M S)$, the spatial resolution is rather low for studying local features of the circulation in the Sea of Azov.

One of the sources of information on the Black Sea hydrophysical fields (the water exchange with them significantly affects the Sea of Azov salinity) is the Marine Forecasting Center of Marine Hydrophysical Institute of RAS (http://mis.bsmfc.net) [2]. The products of this center are provided with $5 \mathrm{~km}$ resolution. In work [3], two regional configurations were proposed for NEMO (Nucleus for European Modeling of the Ocean) model [4], one of which had a similar spatial resolution and allowed performing joint simulations in the Azov and the Black Seas. The results of numerical modeling obtained in [3] using the noted configuration, despite insufficient agreement with high-resolution satellite data, showed less satisfactory quantitative estimates of water exchange through the Kerch Strait than the results of modeling with a higher resolution $(2.5 \mathrm{~km})$.

\footnotetext{
${ }^{2}$ COPERNICUS - Marine Environment Monitoring Service. [online] Available at: http://marine.copernicus.eu/ [Accessed: 01 November 2019].
} 
During the numerical modeling of the dynamics of the Sea of Azov waters, the characteristics of surges are well reproduced [5, 6]. However, the effect of the Black Sea waters influx is often neglected. Therefore, the models for joint circulation of basins [8] with good resolution for the Kerch Strait are more promising for the analysis of long-term changes.

In the present work a similar approach based on NEMO model [4] is implemented to reconstruct the general circulation and trends of hydrophysical parameters in the seas of the Euxinus cascade. The sequence of operations for the preparation and conduction of long-term free run experiments is given. The work consists of an introduction and three sections. Section 2 describes the finalized regional configuration for reconstruction the general circulation in the basins of the so-called Euxinus cascade (the Sea of Azov, the Black Sea and the Sea of Marmara). The procedures for preparing the initial and boundary conditions for carrying out numerical experiments are presented. Section 3 presents a preliminary analysis of the results of long-term free-run simulations for the Sea of Azov basin. Some nuances cannot be fully presented within the framework of this work, therefore they were omitted in order to avoid a significant excess of the paper volume. The discussion presents the results of an indirect comparison of numerical simulation with satellite data on ice cover.

\section{Data and methods}

2.1. The studied area and the general circulation model used

The computational domain is a quasiregular grid covering the basins of the Black, Azov and Marmara Seas with $1 / 24^{\circ} \times 1 / 17^{\circ}$ step in the meridional and zonal directions, respectively (BAMS24) in the WGS84 coordinate system, which corresponds to $\sim 4.6 \mathrm{~km}$. The bottom topography for the configuration is based on the digital array of bathymetry EMODnet ${ }^{3}$ (Fig. 1).

Long-term runs in this work are performed using NEMO ocean numerical modeling framework [4], the hydrodynamic block of which is based on a system of primitive equations of hydrothermodynamics in the Boussinesq approximation and hydrostatics. When choosing the right triple of the local orthogonal basis $\mathbf{i}, \mathbf{j}, \mathbf{k}$ (i is directed to the east, $\mathbf{j}$ is directed to the north, $\mathbf{k}$ is upwards) the system of equations has the following form

$$
\begin{gathered}
\frac{\partial \mathbf{U}_{h}}{\partial t}=-\left[(\nabla \times \mathbf{U}) \times \mathbf{U}+\frac{1}{2} \nabla\left(\mathbf{U}^{2}\right)\right]_{h}-f \mathbf{k} \times \mathbf{U}_{h}-\frac{1}{\rho_{\mathrm{o}}} \nabla_{h} p+\mathbf{D}^{\mathrm{U}}+\mathbf{F}^{\mathrm{U}}, \\
\frac{\partial p}{\partial z}=-\rho g, \\
\nabla \cdot \mathbf{U}=0, \\
\frac{\partial T}{\partial t}=-\nabla(T \mathbf{U})+D^{T},
\end{gathered}
$$

\footnotetext{
${ }^{3}$ EMODnet-Bathymetry portal. [online] Available at: http://www.emodnet-bathymetry.eu [Accessed: 02 February 2018].
} 


$$
\begin{gathered}
\frac{\partial S}{\partial t}=-\nabla(S \mathbf{U})+D^{S}, \\
\rho=\rho(T, S, p), \\
\omega=\frac{\partial \eta}{\partial t}+\left.\mathbf{U}_{h}\right|_{z=\eta} \cdot \nabla_{h}(\eta)+P+R-E,
\end{gathered}
$$

where $\eta$ is the sea level; $P$ is precipitation; $R$ is river runoff; $E$ is evaporation; $\mathbf{F}^{\mathbf{U}}$, $F^{T}, F^{S}$ are the terms describing the external forcing the form of which will be given below; $\mathbf{U}=\mathbf{U}_{h}+w \mathbf{k}$ is a vector of velocity of currents; index $h$ denotes the vector projection onto the plain $\mathbf{O i j}$, i.e. $\mathbf{U}_{h}$ is a horizontal velocity; $f=2 \mathbf{\Omega k}$ is the Coriolis parameter; $\boldsymbol{\Omega}$ is the angular velocity of the Earth.
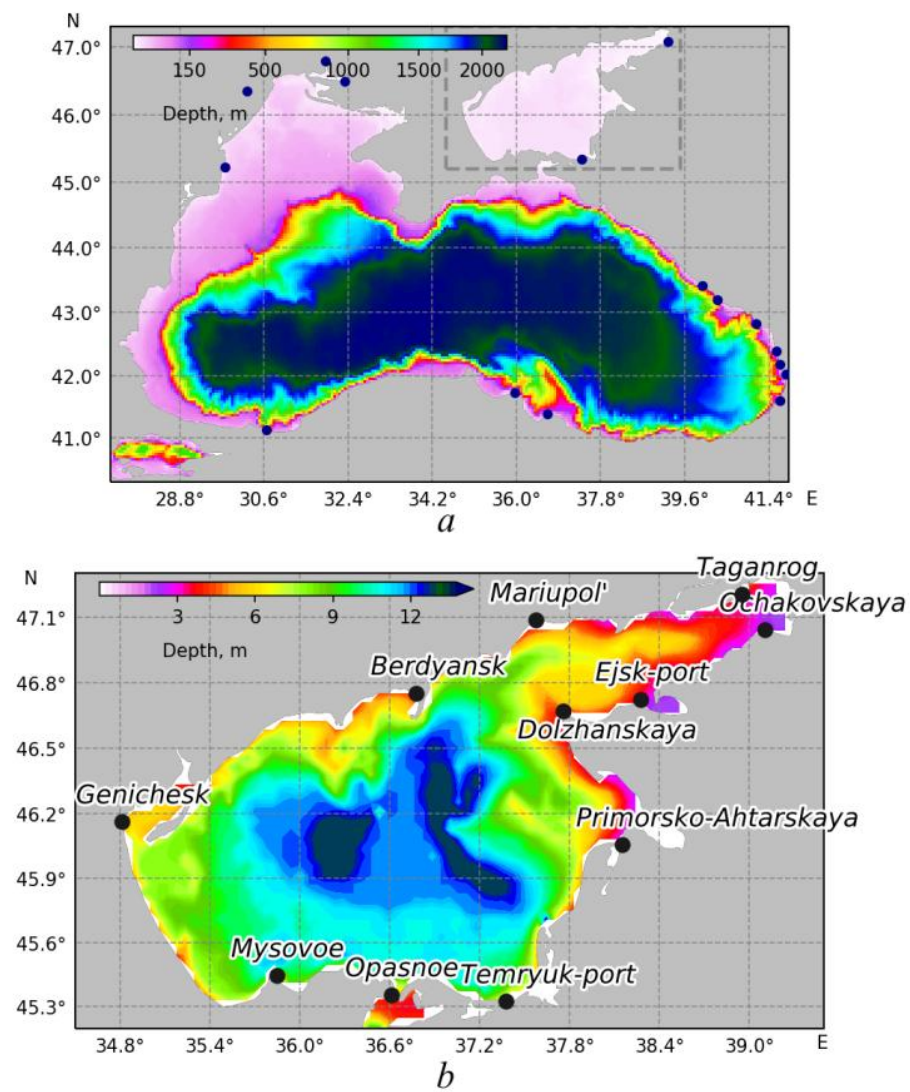

F i g. 1. Computation domain of the BAMS24 configuration: $a$ - bathymetry $(\cdot-$ mouths of the rivers taken into account in simulations); $b$ - zoom of the distinguished area of the Azov Sea $(\bullet-$ location of the coastal hydrometeorological stations, HMS)

The subgrid processes in the equations for momentum (1) $\left(\mathbf{D}^{\mathbf{U}}\right.$ term) and advection -diffusion of heat (4) and salt (5) ( $D^{T}$ and $D^{S}$ terms, respectively) are parameterized as follows. Lateral turbulent exchange is represented by a biharmonic operator with viscosity coefficients $\left(-5 \cdot 10^{9} \mathrm{~m}^{4} / \mathrm{s}\right)$ and heat PHYSICAL OCEANOGRAPHY VOL. 26 ISS. 5 (2019) 
and salt diffusion $\left(-4 \cdot 10^{8} \mathrm{~m}^{4} / \mathrm{s}\right)$. Vertical mixing is determined by the equations of $k$ - $\varepsilon$ closure hypothesis [9]. In this case, the coefficients of turbulent diffusion and viscosity are calculated using the stability function proposed in [10]. The UNESCO formula [11, p.15] is used as the equation of state (6). The remaining notations in the system of equations (1) - (7) are generally accepted ones.

Discretization of the system of equations was performed using Arakawa's $C$ grid [12]. In this case, the momentum equations (1) have the vector form and are approximated by means of a scheme with conservation of energy and enstrophy. For nonlinear terms in the advection - diffusion equations $(4,5)$ the TVD scheme is applied [13]. The $z$-coordinate with a partial step at the bottom is used vertically, which slightly improves the consideration for bathymetry irregularities in comparison with the full step $z$-coordinate, especially in the area of a sharp continental slope. The position of the levels is predetermined using the analytical function proposed by the authors of the model. The noted spatial resolution is obviously not enough in the Bosphorus area. Therefore, in this work, based on a series of numerical experiments the zonal cell size is artificially reduced ("partially closed cells") to obtain adequate rates of water transport through the strait.

Sea level calculation is performed taking into account the kinematic condition on the sea surface (7) [14]. A time-splitting scheme into the barotropic (fast) and baroclinic (slow) modes is used. The time step for a slow mode is 5 minutes, for a fast one $-10 \mathrm{~s}$. Time discretization is carried out by means of a modified "leapfrog" scheme [15].

In the numerical integration of the system of equations the following boundary conditions were used. For lateral boundaries at the coasts the free-slip condition is prescribed for the momentum equations. At the bottom, nonlinear friction is specified. In the advection - diffusion equations of heat (salt) at the lateral boundaries and the bottom the conditions of no fluxes are set and, in addition, the equality to zero of the Laplacian $T(S)$ at the lateral boundaries.

In the Sea of Marmara, westward from the island of Marmara, boundary conditions are set on the open liquid boundary. The average annual variability over 10 years based on $C M E M S^{4}$ products is taken into account: the level and barotropic transport are set using Flather's scheme and the flow relaxation method is used for temperature and salinity profiles.

\subsection{Atmospheric effect}

In numerical experiments the fields of temperature and specific humidity of air at $2 \mathrm{~m}$ level, the components of horizontal wind velocity at $10 \mathrm{~m}$, the fluxes of downward long-wave and short-wave radiation, precipitation in liquid and solid phases from the global atmospheric reanalysis ERA $5^{5}$, which is currently available for a limited 2000-2017 period, are used as an atmospheric forcing. This is the latest generation product from the Center for Medium-Range Weather Forecasts $(E C M W F)$ with $14^{\mathrm{o}}$ spatial resolution and obtained on the basis of a more advanced

\footnotetext{
${ }^{4}$ Global Ocean $1 / 12^{\circ}$ Physics Analysis and Forecast Updated Daily. [online] Available at: http://marine.copernicus.eu/services-portfolio/access-to-products/?option=com_csw\&view=details \&product_id=GLOBAL_ANALYSIS_FORECAST_PHY_001_024 [Accessed: 26 September 2018].
} 
atmospheric model than the generation of ERA-Interim products. The reanalysis fields have a time resolution of $1 \mathrm{~h}$, which may be important for reconstructing short-term (diurnal) processes, for example, storm surges in the Sea of Azov. Using the bulk formulas of the CORE protocol (Coordinated Ocean-ice Reference Experiments) [16], the marked meteorological parameters with initial time discreteness are used to calculate the total heat fluxes, mass and wind stress.

According to the protocol formulas, the upward heat flux from the sea surface depends on the temperature difference between the water and air. Note that a preliminary experiment showed non-physical cooling of water (in some locations up to $-10^{\circ} \mathrm{C}$ ) on the northwestern shelf of the Black Sea and in the Sea of Azov, which clearly demonstrates the need to include an ice model. As can be seen from the reanalysis data (Fig. 2,a), the temperature in winter can fall significantly below $0^{\circ} \mathrm{C}$ for long periods. This indicates the formation of ice in these areas. In addition, this is confirmed by the analysis of in-situ temperature measurements and satellite images for winter. Since the purpose of the first free-run simulations was to assess salinity trends and the ice model required the adjustment of a significant number of parameters, the thermodynamics of ice was not taken into account. Instead, for numerical experiments the correction of the surface boundary conditions was used: at the moment when the water reaches freezing temperature (approximately $0.06^{\circ} \mathrm{C}$ for the salinity of the Sea of Azov) the no heat flux condition is prescribed. The authors note that in this way only indirect characteristics of the ice situation can be obtained. A qualitative analysis of the area proned to ice cover formation, according to the results of a numerical experiment, is presented in the discussion.

In the basin of the Sea of Azov surge processes play an important role. Therefore, it is necessary to take into account the atmospheric pressure field at sea level $P_{\text {atm }}$ as the external effect $\mathbf{F}^{\mathbf{U}}$ in the equations of motion (1), which is usually carried out using the inverse barometer formula:

$$
\eta_{i b}=-\frac{1}{g \rho_{0}}\left(P_{\mathrm{atm}}-P_{0}\right),
$$

where $P_{0}=101000 \mathrm{~Pa}$.

The representation of the interannual variability of the basin averaged wind stress vorticity calculated using the bulk formulas of CORE protocol in one of the experiments is given in Fig. 2, a. As can be seen, the most intense winds are observed in winter, which is consistent with the previous investigations.

It is important to note that the values of the wind rotor are quantitatively high enough to reconstruct adequate circulation in the Black Sea. Therefore, the advantages, compared with other reanalysis products used earlier for such studies, are a fairly high resolution and the presence of a continuous series which will be expanded in the near future.

${ }^{5}$ Copernicus Climate Change Service (C3S) ERA5: Fifth generation of ECMWF atmospheric reanalyses of the global climate, Copernicus Climate Change Service Climate Data Store (CDS). [online] Available at: https://cds.climate.copernicus.eu/ [Accessed: 26 September 2018]. 

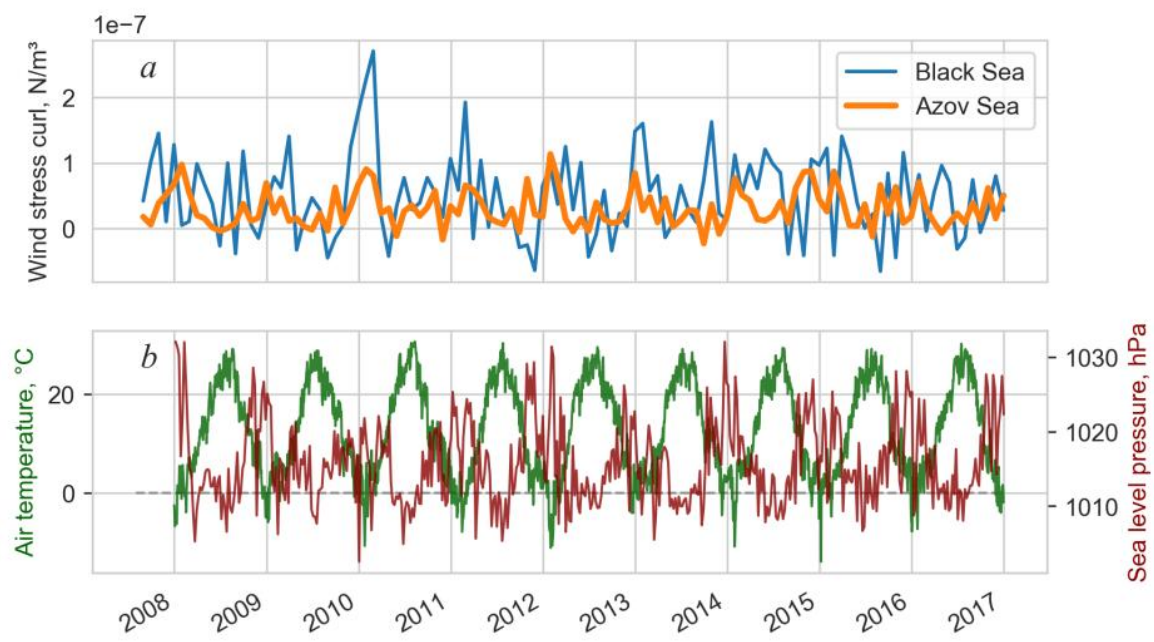

F i g. 2. Surface boundary conditions from the $E R A 5$ reanalysis data: $a$ - the wind stress vorticity averaged over the basins of the Azov and Black seas; $b$ - diurnal variability of air temperature and weekly variability of sea level pressure over the Azov Sea basin

\subsection{River runoff}

The developed regional configuration of the model takes into account the climatic discharges of 16 rivers. The location of the mouths is shown in Fig. 1, $a$. In [17], the seasonal temperature variation and low salinity of the inflowing water ( $2 \%$ ) are specified as boundary conditions in the rivers. The same approach was then used in [3]. The results of preliminary numerical experiments with setting such boundary conditions showed a significant salinization of the Sea of Azov waters, which is poorly consistent with the observational data. Therefore, in the presented free runs the values of temperature and salinity were not set at the mouths of the rivers. Based on the climatic values of the volume discharge of the Black Sea basin ${ }^{1}$ rivers (Fig. 3, a), the salinity values were corrected in the entire liquid column down to the bottom under the assumption that river waters have zero salinity. The water temperature was not corrected. In the Sea of Marmara basin river runoff was not taken into account.

The accuracy of the simulation results in the Sea of Azov basin can be improved if real variability of the river runoff of the water balance are taken into account. For this purpose, observational data ${ }^{6}$ of volumetric runoff of the Don and Kuban rivers were used (Fig. 3,b). For comparison, the climatic data used in previous versions of numerical experiments are presented [3]. As can be seen, the discharge values of the Don River have been decreasing since 2013. A local minimum is observed in the summer of 2015: climatic values for this season are two times higher. In the autumn of the same year there is a local minimum of discharge of the Kuban River, the behavior of which also shows a negative tendency since 2006.

6 Polonsky, V.F. and Ostroumova, L.P., 2018. The Main Hydrological Characteristics of the Sea Estuaries of the European Territory of Russia [Database]. Moscow. State Registration No. 2012620681. 

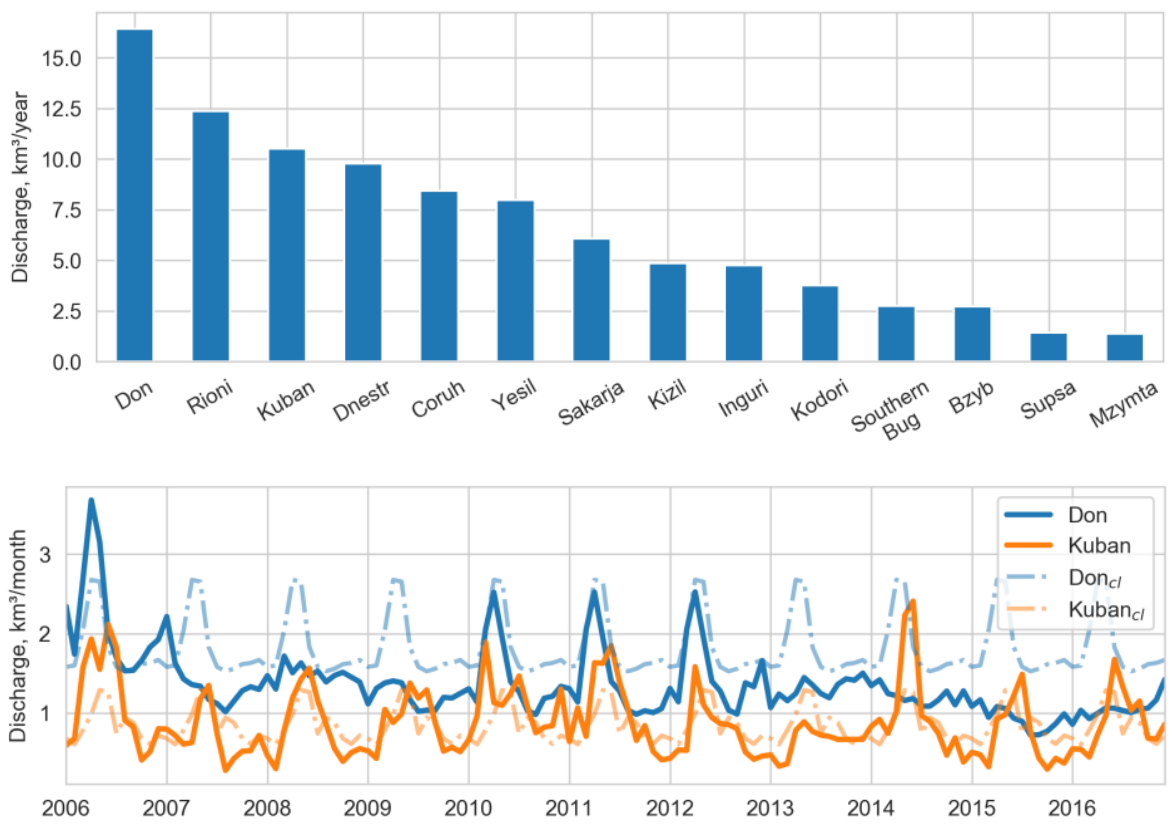

F i g. 3. River runoff in the simulations: $a$ - annual average discharge in all the rivers except for the rivers Danube $\left(\approx 202 \mathrm{~km}^{3} /\right.$ year$)$ and Dnieper $\left(\approx 47 \mathrm{~km}^{3} /\right.$ year$) ; b-$ monthly average discharge $\left(\mathrm{km}^{3} / \mathrm{month}\right)$ for the rivers of the Azov Sea basin based on the observation data ${ }^{6}$ and the climatic values used in [3]

\subsection{Initial conditions}

An important problem for modeling of near real hydrophysical fields in the runs without data assimilation is to prepare the initial conditions. The Sea of Azov is a rather shallow basin and the adaptation of temperature to atmospheric effect will pass quickly enough. We note here that it is convenient to begin numerical experiments in the period when the ice is absent (from early spring to mid-December).

Salinity is a parameter that depends on a large number of external parameters, such as water exchange through the Kerch Strait, river runoff, precipitation and evaporation. Therefore, the initial salinity field should be as close as possible to the observations.

The initial temperature and salinity fields in the Sea of Azov were constructed by optimal interpolation of insitu observations from a combined array of processed data from the Black Sea of $C M E M S^{7}$ service and the SeaDataNet (European Ocean and Marine Data Management Infrastructure) (https://www.seadatanet.org/) oceanographic database. In order to obtain climatic fields, all observations completed within a certain month were assigned to its middle. The greatest availability of observational data falls on August.

\footnotetext{
${ }^{7}$ Black Sea-In-Situ Observations Yearly Delivery in Delayed Mode. [online] Available at: http://marine.copernicus.eu/services-portfolio/access-to-products/?option=com_csw\&view=details \&product_id=INSITU_BS_TS_REP_OBSERVATIONS_013_042 [Accessed: 01 November 2019].
} 
Since the task was to reconstruct the trend at least over the past 10 years, we took 2007 as the initial year. For the Black Sea basin the initial temperature and salinity fields were taken from the reanalysis of the hydrophysical parameters of the Black Sea Marine Forecast Center (BS MFC) (http://mis.bsmfc.net) for August 15, 2007 and for the Sea of Marmara from $C M E M S^{4}$ global analysis for the same date.

The obtained fields $T_{0}$ and $S_{0}$ were interpolated to the domain grid by linear vertical interpolation and horizontal bilinear with extrapolation of a small number of coastal grid points for matching with computational sea cells.

Note that the experience of free runs earlier using temperature and salinity fields and fields of zero current velocities (the state of rest) as the initial conditions showed a pronounced period of the model adaptation, which amounted to about three months [3]. Therefore, an adjustment experiment was preliminarily carried out. Its idea was proposed by academician A.S. Sarkisyan: the fields of current velocities and level are reconstructed from fixed fields $T_{0}$ and $S_{0}$. For this purpose, the sources $F^{T}$ and $F^{S}$, which have the form $F^{T}=-\gamma\left(T-T_{0}\right)$ and $F^{S}=-\gamma\left(S-S_{0}\right)$ where $\gamma$ is the parameter inverse to the relaxation period (relaxation parameter) equal to 12 hours, are included in the right-hand sides of equations (4) - (5). For other components of the sea state vector zero initial conditions (the state of rest) are used. Thus, the temperature and salinity fields during the experiment are adjusted with each other and the current velocities will be adapted to the resulting density field.

The results of the adjustment runs are shown in Fig. 4. In the presented thermohaline fields (Fig. 4, $a, b$ ) both mesoscale structures and elements of the general circulation can be distinguished. Areas of river runoff are well defined (for example, the Taganrog Bay is significantly freshened, the region of the Black Sea waters in the Sea of Marmara basin can be noticed).
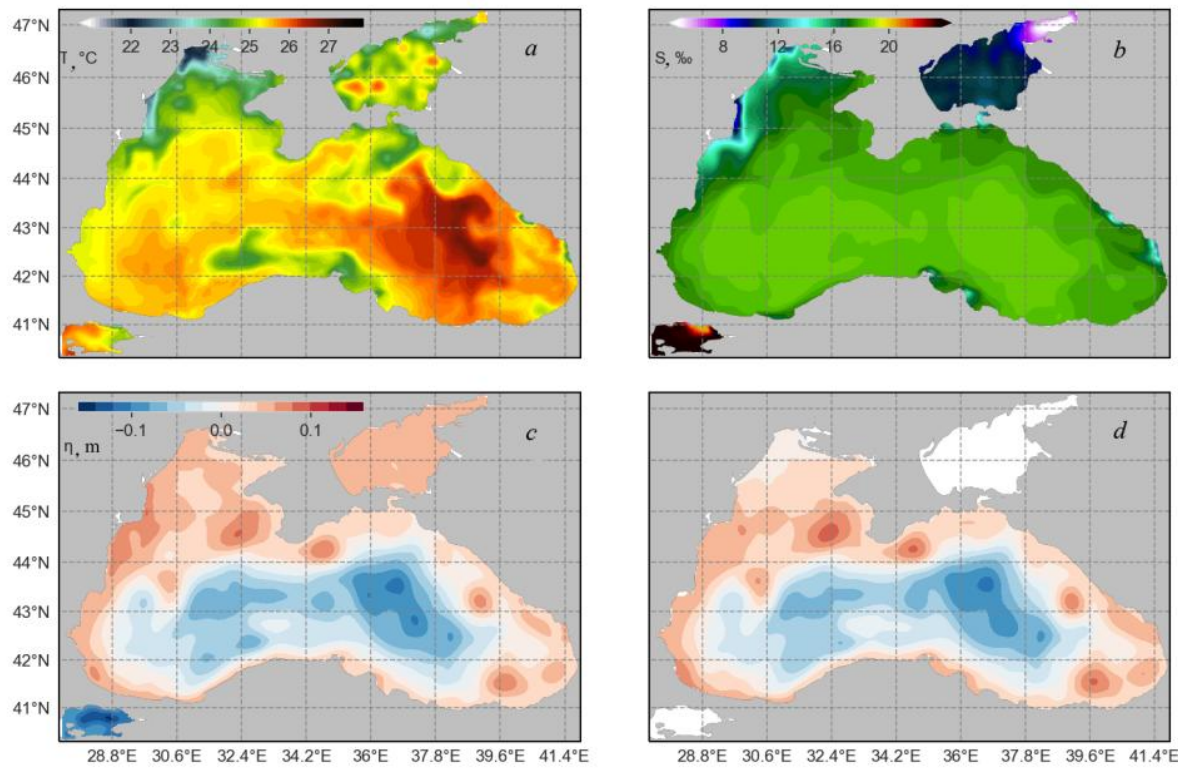

F i g. 4. Fields of initial conditions (August 15, 2007) adapted for the free-run simulations for: $a-$ surface temperature and $b$-surface salinity; $c$-sea level; $d$-sea level from the BS MFC reanalysis for August 15, 2007 (the scale is analogous to that in Fig. 4,c) 
Due to the numerical model effect, the irregularities regions that resulted from the interpolation procedure are smoothed in the hydrophysical fields. In addition, in a numerical experiment adjusted fields of current velocities and sea level were reconstructed (Fig. 4, c). As can be seen, the structure of the sea level corresponds to the results of the reanalysis of BS MFC: the position and intensity of the mesoscale eddies on the right from the Rim Current (RC) are in good agreement (Fig. 4, $c, d$ ). The level difference between the Sea of Azov and the Black Sea, forming a current in the Kerch Strait, is well pronounced, as well as the difference between the Black and Marmara Seas.

\section{The results of free runs}

The positive trend of salinity in different parts of the Sea of Azov basin is evidenced by observations from HMS (Fig. 5). It is important to note that the initial salinity field estimates obtained in Section 2.4 turned out to be quantitatively close to the observations used for verification. Qualitatively, the simulation results reconstruct the behavior of salinity with time at all stations. For example, the certain local maxima are reproduced (Fig. 5, a), as well as the behavior of average trends without taking into account short-term variability (Fig. 5, b).


F i g. 5. Comparison of the results of salinity modeling and observations at the stations Temryuk-port $(a)$, Genichesk ( $b$ ) and in the point closest to the station based on the numerical modeling results; $(c)$ root mean squared (RMS) deviations "model minus observations" in 2008-2016 
Significant variations in salinity are observed at the Genichesk station (range up to $8 \%$ ). The probable cause of them is the inflow of highly saline waters from the Sivash Bay, as well as the salt flux during ice formation period (Fig. 5, b). According to the results of numerical modeling the behavior of salinity only qualitatively reconstructs its growth. The dynamics in the coastal region of this station at the selected resolution cannot be adequately modeled. Note that the maximum values of root-mean-square deviations (RMS) "model minus observations" are also observed at stations lying near the limans or in estuarine areas (Primorsko-Akhtarsk, Yeysk, Temryuk) (Fig. 5, c), which can cause significant deviations on short time scales. In general, the quantitative agreement of salinity at stations according to the results of modeling and observation can be described as satisfactory.

A similar comparison of temperature fields was performed. The temperature behavior according to the results of numerical modeling is qualitatively and quantitatively in good agreement with observations at HMS. Summer temperature maximums are reconstructed by the model in all years except for 2008 and 2010. The length of the winter cooling period is also consistent with the measurements. The maximum root-mean-square deviations "model minus observations" are observed at the stations Taman and Ochakov Spit. As noted above, the spatial resolution of the numerical model is insufficient for reproducing the circulation in such water areas.

\section{Research results and their discussion}

This work presents the first attempt to carry out long-term numerical experiments to simulate the joint circulation of the Black, Azov and Sea of Marmara waters using ERA5 (new-generation atmospheric reanalysis from $E C M W F$ ) product and a new regional configuration of $N E M O$ model.

According to the simulation results, hydrophysical fields in the basins of the Euxinus cascade are in qualitative agreement with previously obtained ideas about circulation in the basins. A more detailed analysis of the Black Sea and the Marmara Sea hydrophysical fields is supposed. A comparison of numerical modeling results with observations in the Sea of Azov showed that the thermohaline characteristics in the performed prognostic experiments are quantitatively reconstructed very satisfactorily. The most important feature that was achieved by numerical modeling is the reproduction of the positive salinity trend of the Azov Sea waters. Note that it was reconstructed despite the insufficient spatial resolution of the developed regional configuration of the model.

The use of heat flux artificial correction on the surface provided the reconstruction of temperature variations at different points in the Sea of Azov in winter. The results obtained when determining the position of the freezing temperature isoline (approximately $-0.06^{\circ} \mathrm{C}$ ) allow us to evaluate indirectly the position of the ice edge in the basin (Fig. 6). As can be seen, the configuration of the supposed ice field in numerical experiments is consistent with other sources of information on the ice cover $[18,19]$. 

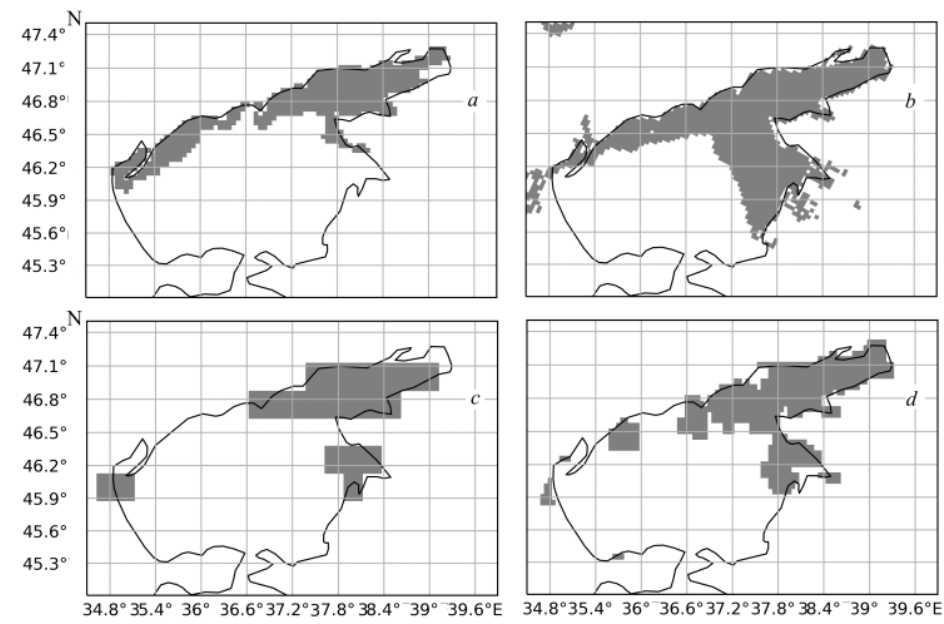

F i g. 6. Estimates of location of the ice edge (grey area) in the Azov Sea basin based on the data of: $a$ - numerical modeling (freezing point isotherm); $b$-Interactive Multisensor Snow and Ice Mapping System (IMS) [26] (resolution $4 \mathrm{~km}), c-$ ERA5 $^{5}$ (sea ice cover) (resolution $0.25^{\circ}$ ), $d-$ OSTIA [19] (resolution $0.05^{\circ}$ )

\section{REFERENCES}

1. Matishov, G.G. and Grigorenko, K.S., 2017. Causes of Salinization of the Gulf of Taganrog. Doklady Earth Sciences, [e-journal] 477(1), pp. 1311-1315. https://doi.org/10.1134/ S1028334X17110034

2. Korotaev, G.K., Oguz, T., Dorofeyev, V.L., Demyshev, S.G., Kubryakov, A.I. and Ratner, Yu.B., 2011. Development of Black Sea Nowcasting and Forecasting System. Ocean Science, [e-journal] 7(5), pp. 629-649. https://doi.org/10.5194/os-7-629-2011

3. Mizyuk, A.I., Senderov, M.V., Korotaev, G.K. and Sarkysyan, A.S., 2016. Features of the Horizontal Variability of the Sea Surface Temperature in the Western Black Sea from High Resolution Modeling. Izvestiya, Atmospheric and Oceanic Physics, [e-journal] 52(5), pp. 570-578. https://doi.org/10.1134/S0001433816050108

4. Madec, G., and the NEMO team, 2008. NEMO Ocean Engine. Note du Pôle de modélisation. Technical Report. [e-book] France: Institut Pierre-Simon Laplace. No. 27. Available at: https:// www.nemo-ocean.eu/doc/node1.html [Accessed: 5 November 2016].

5. Popov, S.K. and Lobov, A.L, 2016. Diagnosis and Forecasts of Flood in Taganrog with the Help of an Operational Hydrodynamic Model. In: Hydrometcentre of Russia, 2016. Proceedings of Hydrometcentre of Russia. Moscow: TRIADA LTD. Iss. 362, pp. 92-108.

6. Fomin, V.V. and Diansky, N.A., 2018. Simulation of Extreme Surges in the Taganrog Bay with Atmosphere and Ocean Circulation Models. Russian Meteorology and Hydrology, [ejournal] 43(12), pp. 843-851. https://doi.org/10.3103/S1068373918120051

7. Zalesny, V.B., Diansky, N.A., Fomin, V.V., Moshonkin, S.N. and Demyshev, S.G., 2012. Numerical Model of the Circulation of the Black Sea and the Sea of Azov. Russian Journal of Numerical Analysis and Mathematical Modelling, [e-journal] 27(1), pp. 95-112. https:// doi.org/10.1515/rnam-2012-0006

8. Stanev, E.V., Grashorn, S. and Zhang, Y.J., 2017. Cascading Ocean Basins: Numerical Simulations of the Circulation and Interbasin Exchange in the Azov-Black-MarmaraMediterranean Seas System. Ocean Dynamics, [e-journal] 67(8), pp. 1003-1025. https:// doi.org/10.1007/s10236-017-1071-2

9. Rodi, W., 1987. Examples of Calculation Methods for Flow and Mixing in Stratified Fluids. Journal of Geophysical Research: Oceans, [e-journal] 92(C5), pp. 5305-5328. https:// doi.org/10.1029/JC092iC05p05305

10. Canuto, V.M., Howard, A., Cheng, Y. and Dubovikov, M.S., 2001. Ocean Turbulence. Part I: One-Point Closure Model - Momentum and Heat Vertical Diffusivities. Journal of Physical Oceanography, [e-journal] 31(6), pp. 1413-1426. https://doi.org/10.1175/15200485(2001)031<1413:OTPIOP>2.0.CO;2 
11. Fofonoff, N.P. and Millard, R.C., 1983. Algorithms for Computation of Fundamental Properties of Seawater. UNESCO, 53 p. Available at: https://unesdoc.unesco.org/ark:/48223/pf0000059832. [Accessed: 10 November 2019].

12. Mesinger, F. and Arakawa, A., 1976. Numerical Methods Used in Atmospheric Models, vol. 1 Geneva: WMO-ICSU Joint Organizing Committee, 76 p.

13. Zalesak, S.T., 1979. Fully Multidimensional Flux-Corrected Transport Algorithms for Fluids. Journal of Computational Physics, [e-journal] 31(3), pp. 335-362. https:// doi.org/10.1016/0021-9991(79)90051-2

14. Roullet, G. and Madec, G., 2000. Salt Conservation, Free Surface, and Varying Levels: A New Formulation for Ocean General Circulation Models. Journal of Geophysical Research: Oceans, [e-journal] 105(C10), pp. 23927-23942. https://doi.org/10.1029/2000JC900089

15. Leclair, M. and Madec, G., 2009. A Conservative Leapfrog Time Stepping Method. Ocean Modelling, [e-journal] 30(2-3), pp. 88-94. https://doi.org/10.1016/j.ocemod.2009.06.006

16. Large, W.G. and Yeager, S.G., 2004. Diurnal to Decadal Global Forcing for Ocean and SeaIce Models: The Data Sets and Flux Climatologies. Boulder: CGD Division of the National Center for Atmospheric Research. doi:10.5065/D6KK98Q6

17. Kubryakov, A.I., 2004. Application of Nested Grid Technology When Creating Hidrophysical Field Monitoring System in the Black Sea Coastal Areas. In: MHI, 2004. Ecological Safety of Coastal and Shelf Zones and Comprehensive Use of Shelf Resources. Sevastopol: ECOSIGidrofizika, (11), pp. 31-50 (in Russian).

18. National Ice Center, 2008, updated daily. IMS Daily Northern Hemisphere Snow and Ice Analysis at $1 \mathrm{~km}, 4 \mathrm{~km}$, and $24 \mathrm{~km}$ Resolutions, Version 1. [4 km]. Boulder: NSIDC. https:// doi.org/10.7265/N52R3PMC [Accessed: 10 November 2019].

19. Donlon, C.J., Martin, M., Stark, J., Roberts-Jones, J., Fiedler, E., Wimmer, W., 2012. The Operational Sea Surface Temperature and Sea Ice Analysis (OSTIA) System. Remote Sensing of Environment, [e-journal] 116, pp. 140-158. https://doi.org/10.1016/j.rse.2010.10.017

About the authors:

Artem I. Mizyuk - Senior Research Associate, Marine Hydrophysical Institute of RAS (2 Kapitanskaya str., Sevastopol, 299011, Russian Federation), Ph.D. (Phys.-Math.), ORCID ID: 0000-0003-4885- 354X, ResearcherID: C-6125-2016, artem.mizyuk@mhi-ras.ru

Gennadiy K. Korotaev - Research Supervisor, Marine Hydrophysical Institute of

RAS (2, Kapitanskaya str., Sevastopol, 299011, Russian Federation), Corresponding Member of Russian Academy of Sciences, Dr. Sci. (Phys.-Math.), professor, ResearcherID: K-3408-2017, gkorotaev@gmail.com

Alexander V. Grigoriev - Leading Research Associate, N.N. Zubov State Oceanographic Institute (6, Kropotkinskiy Ave., Moscow, 119034, Russian Federation), Ph.D. (Phys.-Math.), ORCID ID: 0000-0001-9630-3986, ag-privat@mail.ru

Oksana S. Puzina - Junior Research Associate, Marine Hydrophysical Institute of RAS (2, Kapitanskaya str., Sevastopol, 299011, Russian Federation), ORCID ID: 0000-0002-1637-4475, oksana_puzina@mhi-ras.ru

Pavel N. Lishaev - Junior Research Associate, Marine Hydrophysical Institute of RAS (2 Kapitanskaya str., Sevastopol, 299011, Russian Federation), Scopus Author ID: 57193071072, pavellish@mail.ru

Contribution of the co-authors:

Artem I. Mizyuk - preparation of NEMO configuration, heat flux correction tests, model runs, data processing, intercomparison of simulation results against observations, preparation of graphic materials, preparation of the paper text

Gennadiy K. Korotaev - statement of the problem, correction of the paper, consulting support

Alexander V. Grigoriev - providing the observational data from hydrometeorological stations, consulting support

Oksana S. Puzina - preparation of the inital conditions for the Sea of Azov, comparison of simulations with different satellite products, preparation of graphic materials

Pavel N. Lishaev - preliminary analysis of data from hydrometeorological stations against simulations

All the authors have read and approved the final manuscript.

The authors declare that they have no conflict of interest. 